\title{
Chylothorax: report of a case complicating ductus ligation through a median sternotomy, and review
}

\author{
T.K.KA U L, W. H. B A I N, M.A. T U R N R , \\ a nd K. M. T A Y L O R \\ University Department of Cardio-Thoracic Surgery, Royal Infirmary, Glasgow
}

\begin{abstract}
Kaul, T. K., Bain, W. H., Turner, M. A., and Taylor, K. M. (1976). Thorax, 31, 610-616. Chylothorax: report of a case complicating ductus ligation through a median sternotomy, and review. An unusual case of chylothorax is described in a 4-year-old child after repair of a ventricular septal defect and ligation of a patent ductus arteriosus through a median sternotomy. Left chylothorax developed after a latent period of six days and was treated initially with continuous drainage and parenteral supplementation of proteins and lipids. Operative intervention with oversewing of the site of the leak in the anterior mediastinum proved necessary after three weeks. The anatomical variations of the thoracic duct are outlined to explain the occurrence of chylothorax after diverse intrathoracic operations. The physiological effects of a thoracic duct fistula and various aspects of management are reviewed.
\end{abstract}

Chylothorax was first described by Bartolet in 1633. Subsequent reviews of chylothorax are summarized in Table I.

Post-thoracotomy chylothorax has usually followed procedures carried out in close proximity to the normal anatomical course of the thoracic duct. It is rare for this complication to follow surgical procedures in areas remote from the thoracic duct (Maloney and Spencer, 1956; Garamella, 1958; Glenn et al., 1965; Tandon, 1968).

This communication describes an unusual case of chylothorax resulting from injury to the left internal thoracic lymph trunk, which allowed retrograde flow of chyle from the thoracic duct via the left bronchomediastinal trunk. The anatomical, physiological, and aetiological aspects of thoracic duct injury are reviewed and the management of iatrogenic chylothorax is discussed.

\section{CASE REPORT}

A 4-year-old girl underwent closure of a ventricular septal defect and ligation of patent ductus arteriosus on 1 April 1974. Preoperatively she was ill with severe pulmonary hypertension and incipient cardiac failure. Surgical approach was through a median sternotomy, the ductus waso doubly ligated, and the ventricular septal defect 3 was closed during heart-lung bypass. The early? postoperative period was uneventful.

On the sixth postoperative day she became acutely short of breath and hypoxic with signs of peripheral circulatory failure. A chest radio- graph showed a mediastinal opacity, fluid in the left chest, and partial collapse of the left lung.

She improved after tracheostomy, the insertion of an intercostal drain into the left pleural space,o and re-inflation of the left lung. At the time of insertion, the chest drain yielded $400 \mathrm{ml}$ ofo creamy fluid. The child was not toxic, had no elevation of temperature, and had a normal white cell count. The fluid was sterile on culture; micro- $N$ scopy revealed no pus cells or micro-organisms but showed the presence of lymphocytes ando chylomicrons. The diagnosis of chylothorax waso thus established.

For the next 18 days drainage of chyle con $\stackrel{\infty}{+}$ tinued at a fairly constant rate, averaging 0 $265 \mathrm{ml} / 24$ hours. That is, about $10 \%$ of her blood volume per day. Towards the end of the third $\stackrel{\mathbb{\perp}}{\circ}$ week drainage showed no signs of abatement; $\mathbb{\mathbb { Q }}$ 4.6 litres of chyle had been lost and serial bloodo 


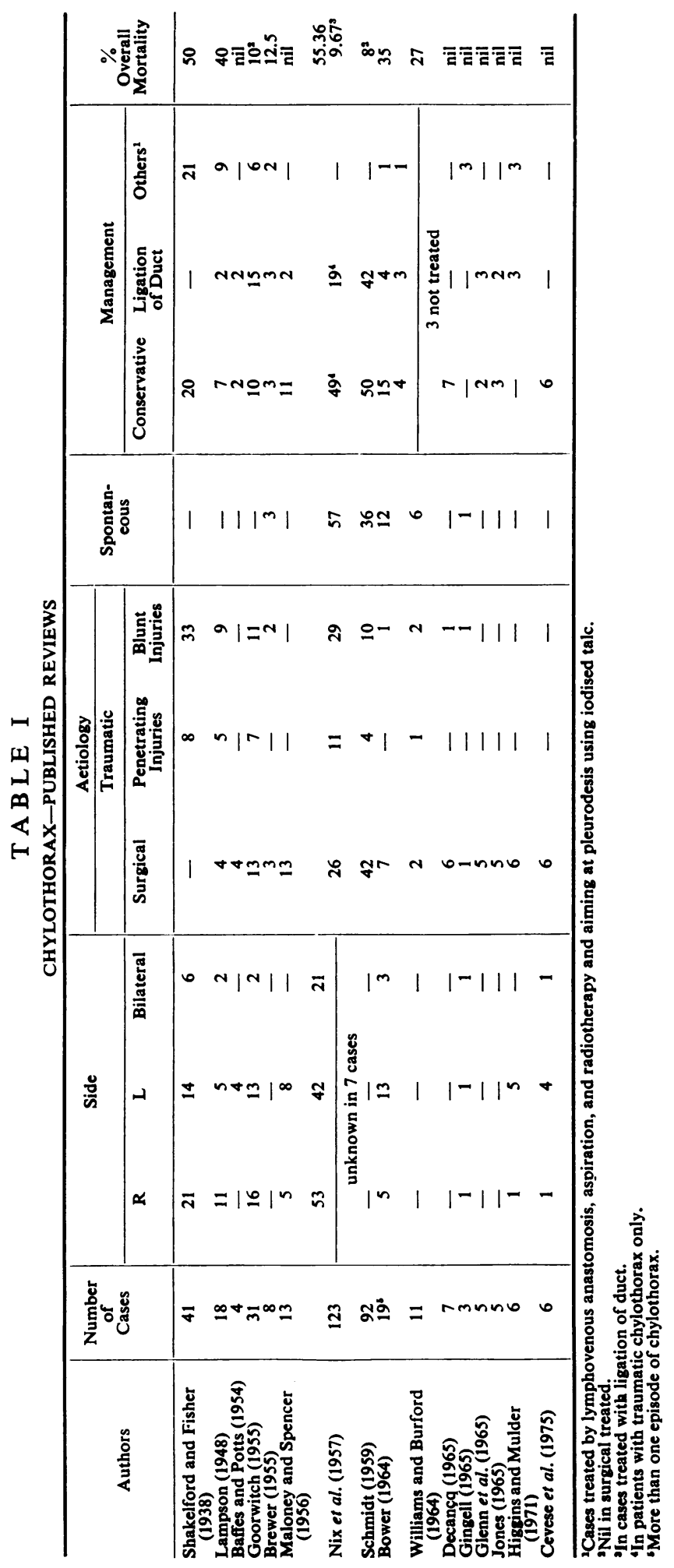


analysis showed progressive depletion of fats, proteins, and lymphocytes (Table II).

On the 19th day, the intercostal drain ceased to function and chyle reaccumulated in the left pleural cavity. The chest was explored through a left anterolateral thoracotomy. The site of ligation of the ductus arteriosus was explored but no leak was found. On further exploration chyle was seen to be seeping from the anterosuperior mediastinum from what appeared to be a left parasternal lymph node, and on pressure a jet of chyle was seen to escape from this structure. This was excised and its pedicle oversewn. The chest was closed with conventional intercostal drainage. After this operation no further chyle appeared in the pleural fluid, and the child went home 10 days later. The total period in hospital was 28 days. During her postoperative recovery, serum proteins and lipids and lymphocyte count rose steadily to preoperative levels and she gained weight.

\section{ANATOMICAL COURSE AND VARIATIONS OF THORACIC DUCT}

COURSE The thoracic duct begins at the upper end of the cisterna chyli near the lower border of the 12th thoracic vertebra and enters the thorax through the aortic opening of the diaphragm. It ascends through the posterior mediastinum and, opposite the fifth thoracic vertebra, inclines to the left, enters the superior mediastinum, and runs along the left side of the oesophagus. Passing into the neck, it ascends 3-4 $\mathrm{cm}$ above the clavicle and finally descends to open into the jugulosubclavian junction.

VARIations Van Pernis (1949) described the variations of thoracic duct encountered in 1081 postmortem specimens. A single duct was found in 663 cases $(61.3 \%)$; two or more branches, which may form a plexiform interlacement, were found in 418 cases $(38.7 \%$ ) (Fig. 1). The level of? crossing from right to left was at the fifth thoracic vertebra in 480 , and at the sixth vertebres in 601 cases. Below the level of crossing, thoracicduct fistula usually results in right-sided chylous effusion, and above this level in a left-sidec $\vec{\omega}^{\circ}$ effusion (Ross, 1961).

TERMINATION The duct terminates by entering the internal jugular, subclavian or innominateir vein. The duct may enter the vein via one or more? terminal endings (Greenfield and Gottlieb, 1956). A number of variations have been described at the site of termination (Greenfield and Gottlieb $\overrightarrow{0}$ 1956; Romanes, 1972).

The thoracic duct contains valves which corres $\frac{0}{0}$ pond to the site of possible external pressure $\stackrel{\mathbb{D}}{-}$ Those at the cephalic end are not always $\operatorname{com} \overrightarrow{\overrightarrow{0}}$ petent (Basmajian, 1971), and a retrograde flows of chyle is possible (Thomas and McGoon, 1971)

TRIBUTARIES (Fig. 2) The important tributaries are the left jugular, left subclavian, and, occas ionally, the left bronchomediastinal lymph trunks $\frac{0}{\infty}$ Efferents from the tracheobronchial and broncho음 pulmonary nodes join to form the broncho $\overrightarrow{\overrightarrow{0}}$ mediastinal trunks. The anterior mediastina lymph nodes, which are scattered in front of the innominate vein, send their efferents, with those of the parasternal nodes, to join the broncho mediastinal trunk. The bronchomediastinal trunk on the left side begins at the root of the lung and ascends lateral to the ductus arteriosus and the arch of aorta. Here it is immediately anterior ton. the vagus nerve. Continuing in a cephalic direc $\frac{\text { O }}{3}$ tion, it joins a large plexus of lymph vessels

T A B L E I I

CASE OF CHYLOTHORAX: DETAILS OF CASE STUDY

\begin{tabular}{|c|c|c|c|c|c|c|c|}
\hline & $\begin{array}{l}\text { Total } \\
\text { Proteins } \\
(\mathrm{g} / \mathrm{I})\end{array}$ & $\underset{(g / 1)}{\operatorname{Albumin}}$ & $\begin{array}{l}\text { Globulins } \\
(\mathrm{g} / \mathrm{l})\end{array}$ & $\begin{array}{l}\text { Triglycerides } \\
\text { as Triolein } \\
(\mathrm{mmol} / \mathrm{l})\end{array}$ & $\begin{array}{l}\text { Cholesterol } \\
(\mathrm{mmol} / \mathrm{l})\end{array}$ & $\underset{\text { Count }}{\text { Lymphocyte }}$ & $\underset{(\mathrm{kg})}{\operatorname{Body} W_{t}}$ \\
\hline Preop. & 70 & 50 & 20 & - & - & 2500 & 15 \\
\hline $\begin{array}{l}\text { Chyle leak } \\
\text { 2nd day } \\
\text { 8th day } \\
\text { 16th day }\end{array}$ & $\begin{array}{l}54 \\
58 \\
57\end{array}$ & $\begin{array}{l}30 \\
30 \\
37\end{array}$ & $\begin{array}{l}24 \\
28 \\
20\end{array}$ & $\begin{array}{l}1 \cdot 46 \\
1 \cdot 41 \\
1 \cdot 26\end{array}$ & $\begin{array}{l}4 \cdot 25 \\
4 \cdot 1 \\
2 \cdot 83\end{array}$ & $\begin{array}{l}1800 \\
1680 \\
1500\end{array}$ & $\begin{array}{l}15 \\
14 \cdot 5 \\
14 \cdot 2\end{array}$ \\
\hline $\begin{array}{l}\text { Chyle leak closed } \\
\text { 2nd day } \\
\text { 5th day } \\
\text { 10th day }\end{array}$ & $\begin{array}{l}53 \\
57 \\
68\end{array}$ & $\begin{array}{l}37 \\
32 \\
40\end{array}$ & $\begin{array}{l}21 \\
25 \\
28\end{array}$ & $\begin{array}{l}1 \cdot 46 \\
2 \cdot 09 \\
2 \cdot 25\end{array}$ & $\begin{array}{l}3 \cdot 74 \\
5 \cdot 34 \\
6 \cdot 5\end{array}$ & $\begin{array}{l}1530 \\
1840 \\
2400\end{array}$ & $\begin{array}{l}14 \cdot 2 \\
14 \cdot 5 \\
15 \cdot 2\end{array}$ \\
\hline \multicolumn{8}{|c|}{$\begin{array}{r}\text { Conversion: SI to traditional units-Triglycerides: } 1 \mathrm{mmol} / 1 \approx 88.5 \mathrm{mg} / 100 \mathrm{ml} \\
\text { Cholesterol: } 1 \mathrm{mmol} / \mathrm{l} \approx 38.6 \mathrm{mg} / 100 \mathrm{ml} .\end{array}$} \\
\hline
\end{tabular}



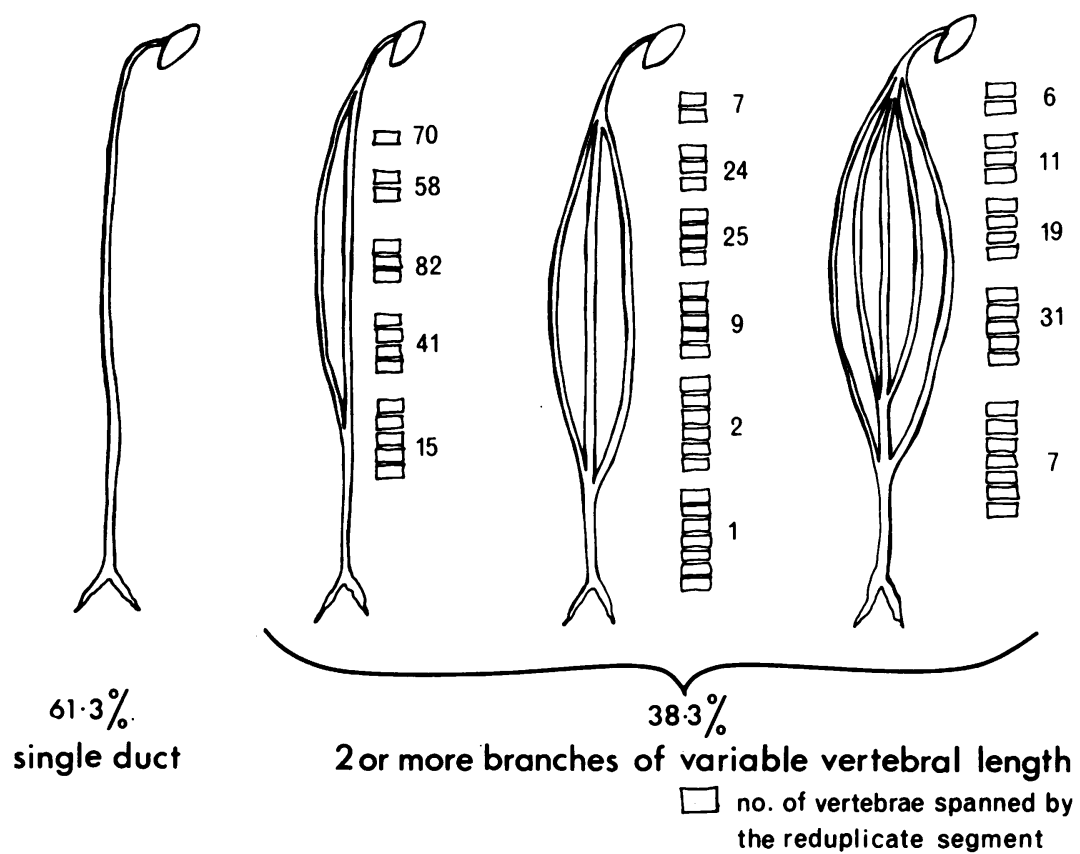

FIG. 1. Variations of thoracic duct (From Van Pernis (1949)). arranged along the left brachiocephalic vein. At each end of this plexus it is joined by the internal thoracic lymph trunk (formed by efferents from parasternal nodes), then it communicates either directly with the veins or joins the upper end of the thoracic duct just before its termination. The right bronchomediastinal trunk ascends beside the trachea, mainly anteriorly and to its right. It communicates with large lymph trunks which ascend along the oesophagus and usually terminates independently in the veins; rarely it may terminate in the right lymph trunk.

\section{PHYSIOLOGICAL CONSIDERATIONS}

About $1500-2400 \mathrm{ml}$ of chyle empties into the venous system daily in an adult. This flow is increased by food or fluid intake and is reduced by starvation. The forward flow of chyle is influenced by intra-abdominal and intrathoracic pressure changes, smooth muscle contractions of the duct wall, adjacent arterial pulsations, and the blood flow in the great veins (Bower, 1964).
Chyle is a milky or creamy white, alkaline, odourless fluid. Its specific gravity varies between 1.012 and 1.020 (Nix et al., 1957). Its appearance is considerably altered by changes in the diet and its fat content. In starvation and while the patient is on a fat-free diet it appears thin and watery.

The thoracic duct is the main pathway for the return of fats and extracellular plasma proteins to the circulation. Fats are absorbed as chylomicrons ( $5 \mu$ in diameter) composed essentially of triglycerides (81-97\%), cholesterol, and phospholipids (Wiseman, 1964). The majority of the fatty acids containing more than 10 carbon atoms are returned through the thoracic duct as esterified fatty acids. Fatty acids with fewer than 10-12 carbon atoms are transported into the portal venous blood as unesterified or free fatty acids (Wiseman, 1964).

The electrolyte, protein, lipid, and sugar contents of chyle may approximate to those of serum but are subject to wider variation with diet (Crandall, Barker, and Graham, 1943). Lymphocytes predominate as its cellular element (Bower, 


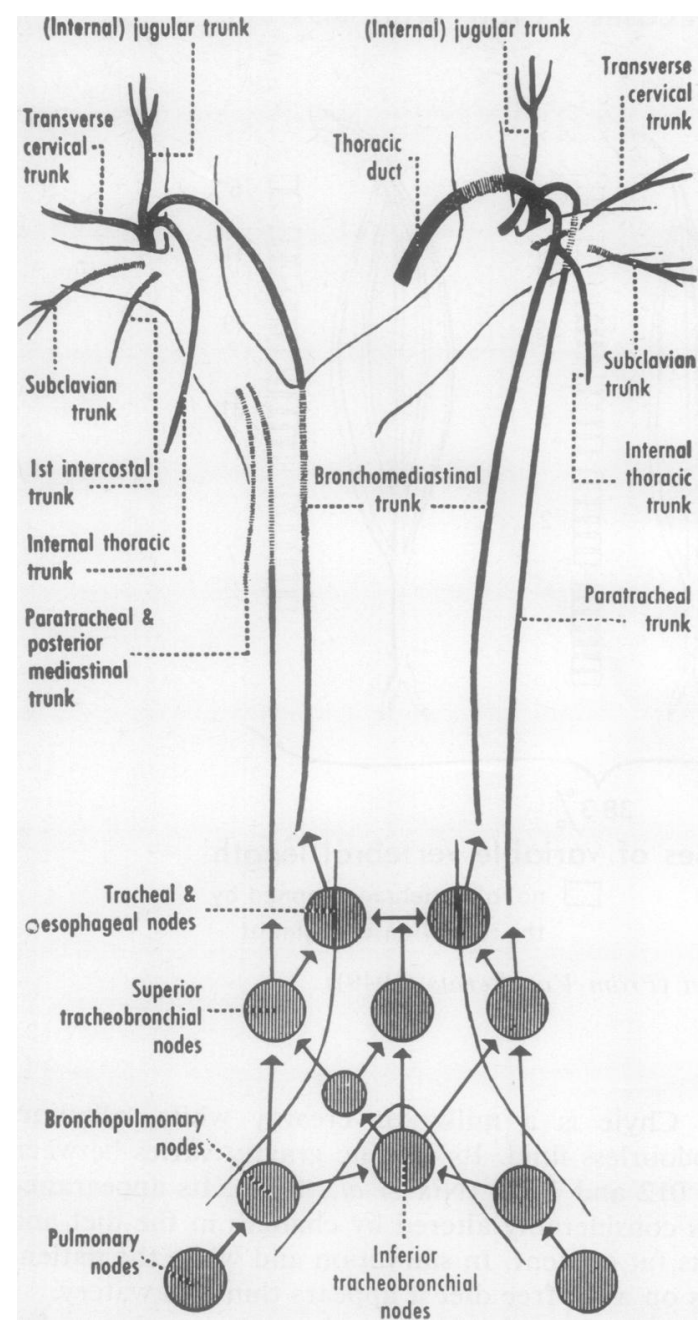

FIG. 2. Tributaries of thoracic duct and formation of bronchomediastinal trunks (Reproduced from Gardner, E., Gray, D. J., and O'Rahilly, $R$. Anatomy, 4th ed., p. 330. W. B. Saunders Co., Philadelphia, 1975).

1964). The thoracic duct is also the route by which most of the lymphocytes produced in the reticuloendothelial system are introduced into the circulation (Yoffey and Courtice, 1956).

Chyle is sterile and bacteriostatic; cultures of Escherichia coli and Staphylococcus aureus fail to multiply in pure chyle (Lampson, 1948). This bacteriostatic property is attributed to the presence of fatty acids and may account for the fact that empyema rarely complicates chylothorax:

A continuing loss of chyle results in severe wasting and may eventually lead to death. Little Harrison, and Blalock (1942) described a patien who sustained a loss of 500 litres of chyle ovê 18 months and in whom 158 litres of chyle (pros tein content $25 \mathrm{~g} /$ day) was removed in a six month period.

\section{AETIOLOGY OF CHYLOTHORAX}

The various causes of chylothorax have beeip classified by Nix et al. (1957) and Bower (1964) Traumatic and neoplastic involvement of the thoracic duct are the commonest causes of chylothorax. Most of the earlier cases collected by Shakelford and Fisher (quoted by Goorwitch, 1955) were due to closed-chest injuries or pen forating injuries from bullet or stab wound hyperextension injuries of the spine, especiall after an automobile accident, may also result int chylothorax (Goorwitch, 1955).

Iatrogenic chylothorax has been reported from time to time after a diverse range of operations (Table III), especially involving the great vessels io the thorax. Its occurrence after intrapericardi operations is rare.

Spontaneous chylothorax due to sudden in crease in intrathoracic or intra-abdominal pressure $\overrightarrow{\widehat{e}}$ (Lampson, 1948), extrinsic compression, and in trinsic destruction (Nix et al., 1957; Bower, 196 have also been described.

\section{MANAGEMENT}

A latent interval between the time of injury ti the duct and the appearance of a chylous effusion has frequently been described (Randolph and Gross, 1957; Garamella, 1958; Tandon, 1968, Higgins and Mulder, 1971); during this period the chyle accumulates underneath the mediastinat pleura and finally breaks through to enter the pleural cavities. This usually occurs after $2-1 \bar{B}$ days but latent intervals of up to six weeks have been reported (Higgins and Mulder, 1971). The clinical picture varies with the amount of chyle lost but has certain common features, namely, a effusion, cardiorespiratory distress, appearance of chyle through intercostal drainage tubes of leakage of chyle from the wound.

The diagnosis may be established by chemicap analysis of the fluid and by microscopic detectiof of the chylomicrons. Serial estimation of lipids proteins, and lymphocyte count are useful i⿺ monitoring the consequences of the chyle loss. 
T A B L E I I I

IATROGENIC CHYLOTHORAX FOLLOWING DIVERSE SURGICAL PROCEDURES (FROM LITERATURE)

Extrapericardial
For Fallot's tetralogy
Blalock
Potts
Glenn
Unclassified
Ligation of PDA
Division of PDA
Repair of coarction of aorta
Glenn's operation
Ligation of anomalous
subclavian artery
Division of vascular ring
Intrapericardial
Brock valvotomy
Closure of VSD
Repair of VSD and partial
anomalous venous return
Repair of pulmonary atresia
VSD, PDA

Cardiovascular operations unclassified

Pulmonary operations

Apicolysis and thoracoplasty

Pulmonary resection for malignancy

Resection for pulmonary TB

Lysis of pulmonary adhesions

Oesophageal operations

Oesophageal resection

Repair of hiatus hernia

Thoracic and thoracolumbar sympathectomy

Costovertebral surgery

Radical neck surgery
Treatment consists of (1) the establishment of effective drainage of the pleural cavity with reexpansion of the lung; (2) the replacement of fats, proteins, and fluid lost; and (3) surgical repair of the leak in a majority of cases.

In a number of cases, simple drainage of the pleural space with consequent re-expansion of the lung will be followed by spontaneous closure of the leak (Decançq, 1965; Chavez and Conn, 1966). Maloney and Spencer (1956) treated 11 patients by multiple aspirations and two patients subsequently required ligation of the duct.

Parenteral supplementation of lipids and proteins may be necessary (Tandon, 1968). Restriction of fats in the diet diminishes the flow of chyle and helps in early closure of the defect. Diet containing medium-chain triglycerides (less than 12 carbon atoms) may be a valuable adjunct in the clinical management of chylous fistula since they are absorbed directly into the blood stream and do not enter the thoracic duct system (Hashim et al., 1964).

Where the leak continues after conservative management for one to two weeks, most authorities would agree that it should be closed surgically. Efforts should first be made to identify the site of the leak.

Location of the site of injury in the thoracic duct is frequently difficult due to fibrin exudates, adhesions, and collapse of the duct itself. A large number of supravital and radio-opaque dyes have been used with variable success to demonstrate the site of thoracic duct injury before or during the operative procedure (Chavez and Conn, 1966; Higgins and Mulder, 1971; Stranahan et al.,
1956). In practice, pooling of dye, staining of the surrounding tissues and obliterative adhesions make precise localization of the site of leak difficult.

Having localized the defect, the duct should be ligated on either side of the defect. In the presence of multiple leaks, when the tissues are soaked with chyle, it is usually sufficient to suture the mediastinal pleura at the site of the leak (Ross, 1961). Where duct injury is detected during the course of an intrathoracic operation, ligation of the duct just above the diaphragm has been recommended (Glenn, 1969).

We are grateful to Professor G. J. Romanes, University of Edinburgh, for help and advice on the anatomical aspects. We thank Miss Black and Miss Hutton for secretarial help.

\section{REFERENCES}

Baffes, T. G. and Potts, W. J. (1954). Postoperative chylothorax. Annals of Surgery, 139, 501.

Bartolet (1633). Quoted in Bower, G. C. (1964).

Basmajian, J. N., ed. (1971). Grant's Method of Anatomy, 8th edition, p. 480. Williams and Wilkins, Baltimore.

Bower, G. C. (1964). Chylothorax: observations in 20 cases. Diseases of the Chest, 46, 464.

Brewer, L. A. (1955). Surgical management of lesions of the thoracic duct. American Journal of Surgery, 90, 210.

Cevese, P. G., Vecchioni, R., D'Amico, D. F., Cordiano, C., Biasiato, R., Favia, G., and Farello, G. A. (1975). Postoperative chylothorax: 6 cases 
in 2,500 operations, with a survey of the world literature. Journal of Thoracic and Cardiovascular Surgery, 69, 966.

Chavez, C. M. and Conn, J. H. (1966). Thoracic duct laceration: closure under conservative management based on lymphangiography evaluation. Journal of Thoracic and Cardiovascular Surgery, 51, 724.

Crandall, L. A., Jr., Barker, S. B., and Graham, D. G. (1943). A study of the lymph flow from a patient with thoracic duct fistula. Gastroenterology, 1, 1040.

Decançq, H. G., Jr. (1965). The treatment of chylothorax in children. Surgery, Gynaecology and Obstetrics, 121, 509.

Gardner, E., Gray, D. J., and O'Rahilly, R. (1973). Anatomy, 4th edition, p. 330. Saunders, Philadelphia.

Garamella, J. J. (1958). Chylothorax treated by ligation of thoracic duct and studies in thoracic ductography. Archives of Surgery, 76, 46.

Gingell, J. C. (1965). Treatment of chylothorax by producing pleurodesis using iodized talc. Thorax, 20, 261.

Glenn, W. W. L. (1969). The Glenn operation: superior vena cava-pulmonary artery anastomosis. In Operative Surgery, edited by C. Rob and R. Smith, vol. II, Thorax, edited by W. P. Cleland. 2nd edition, p. 240. Butterworths, London.

Glenn, W. W. L., Ordway, N. K., Talner, N. S., and Call, E. P., Jr. (1965). Circulatory bypass of the right side of the heart. VI. Shunt between superior vena cava and distal right pulmonary artery; report of clinical application in 38 cases. Circulation, 31, 172.

Goorwitch, J. (1955). Traumatic chylothorax and thoracic duct ligation: case report and review of literature. Journal of Thoracic Surgery, 29, 467.

Greenfield, J. and Gottlieb, M. I. (1956). Variations in the terminal portion of the human thoracic duct. AMA Archives of Surgery, 73, 955.

Hashim, S. A., Roholt, H. B., Babayan, V. K., and Van Itallie, T. B. (1964). Treatment of chyluria and chylothorax with medium-chain triglyceride. New England Journal of Medicine, 270, 756.

Higgins, C. B. and Mulder, D. G. (1971). Chylothorax after surgery for congenital heart disease. Journal of Thoracic and Cardiovascular Surgery, 61, 411.

Jones, J. C. (1965). Twenty-five year experience with the surgery of patent ductus arteriosus. Journal of Thoracic and Cardiovascular Surgery, 50, 149.
Lampson, R. S. (1948). Traumatic chylothorax. Journa of Thoracic Surgery, 17, 778.

Little, J. M., Harrison, C., and Blalock, A. (1942) Chylothorax and chyloperitoneum. Surgery, 11, 392.

Maloney, J. V. and Spencer, F. C. (1956). The non operative treatment of traumatic chylothorax. Surgery, 40, 121.

Nix, J. T., Albert, M., Dugas, J. E., and Wendt, D. L $\overrightarrow{-}$ (1957). Chylothorax and chylous ascites: a study of 302 selected cases. American Journal of
Gastroenterology, 28, 40.

Randolph, J. G. and Gross, R. E. (1957). Congenitafw chylothorax. $A M A$ Archives of Surgery, 4, 405. ir

Romanes, G. J. ed. (1972). Cunningham's Textbookं of Anatomy, 11 th edition, p. 944. Oxford Univer $\overrightarrow{0}$ sity Press, London.

Ross, J. K. (1961). A review of the surgery of the thoracic duct. Thorax, 16, 12.

Schmidt, A. (1959). Chylothorax: review of 5 years cases in the literature and report of a case. Act\&্ Chirurgica Scandinavica, 118, 5.

Stranahan, A., Alley, R. D., Kausel, H. W., ande Reeve, T. S. (1956). Operative thoracic ductography. Journal of Thoracic Surgery, 31, 183.

Tandon, R. K. (1968). Chylothorax after repair ob ventricular septal defect. Journal of Thoracic ans Cardiovascular Surgery, 56, 378.

Thomas, C. S., Jr. and McGoon, D. C. (1971). Isolateकी massive chylopericardium following cardiopul $\$$ monary bypass. Journal of Thoracic and Cardio vascular Surgery, 61, 945.

Van Pernis, P. A. (1949). Variations of the thoracic duct. Surgery, 26, 806.

Williams, K. R. and Burford, T. H. (1964). The management of chylothorax. Annals of Surgery $160,131$.

Wiseman, G. (1964). Absorption from Intestine, p. 85: Academic Press, London and New York.

Yoffey, J. M. and Courtice, F. C. (1956). Lymphatics, Lymph and Lymphoid Tissue, 2nd edition? Arnold, London.

Requests for reprints to: W. H. Bain, FRCS, Univero sity Department of Cardio-Thoracic Surgery, Royäb Infirmary, Glasgow G4. 